\title{
Lepadarg

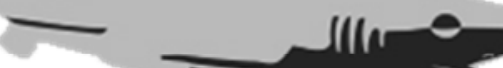

EXPLORANDO A HISTÓRIA E A ARQUEOLOGIA DA COLONIZAÇÃO GREGA (PERÍODOS ARCAICO E CLÁSSICO): FONTES, MÉTODOS, QUESTÕES EXPLORING THE HISTORY AND ARCHAEOLOGY OF THE GREEK COLONIZATION (ARCAIC AND CLASSIC PERIODS): SOURCES, METHODS AND QUESTIONS

Arianna Esposito Airton Pollini 


\title{
Explorando a história e a arqueologia da colonização grega (períodos arcaico e clássico): fontes, métodos, questões ${ }^{1}$
}

\author{
Arianna Esposito ${ }^{2}$ \\ Airton Pollini ${ }^{3}$
}

\begin{abstract}
Resumo: A temática da colonização grega nos Períodos Arcaico e Clássico faz parte de um conjunto de debates historiográficos recentes e destaca os vieses antigos e modernos no estudo das mobilidades individuais e coletivas dos antigos gregos. A Antiguidade se faz, assim, muito atual.
\end{abstract}

Palavras-chave: Colonização; Historiografia; Estudos pós-coloniais; Migrações; Diásporas.

\begin{abstract}
The issue of Greek colonization in Archaic and Classic periods stands from a set of recent historiographical debate and it underlines ancient and modern standpoints in the study of Greek individual and collective mobility. Antiquity becomes thus very present.

Keywords: Colonization; Historiography; Postcolonial Studies; Migrations; Diaspora.
\end{abstract}

Este dossiê tem a intenção de apresentar e de propor um debate acerca dos principais conceitos e das práticas relativas às mobilidades de grandes contingentes de população grega na bacia mediterrânica entre o início do século VIII e o século IV a.C., pouco antes das conquistas de Alexandre o Grande, que marcam uma mudança decisiva na forma e na direção dos deslocamentos dos gregos na Antiguidade. Esta problemática é, atualmente, objeto de discussão, não somente em uma perspectiva internacional (cf. o debate no número especial da revista Ancient West and East (AWE), n. 10, 2011, em particular as contribuições de DOMíNGUEZ, 2011 e GRECO, 2011; ver também MALKIN, 2002; 2004), mas também no âmbito mais específico da pesquisa francesa sobre a história grega (MARTINEZ-SÈVE, 2012; COLLINBOUFFIER, 2012; CAPDETREY, ZURBACH, 2012). No que diz respeito às primeiras fases da colonização, um congresso foi organizado em Roma em 2012, com o objetivo de testar nossos modelos de interpretação pela confrontação das diferentes abordagens contemporâneas, em particular anglófonas e italianas (DONNELLAN, NIZZO, BURGERS, 2016a; DONNELLAN, NIZZO, BURGERS, 2016b; para nossa intervenção: ESPOSITO, POLLINI, 2016).

A pertinência do próprio conceito de colonização foi questionada há cerca de vinte anos (OSBORNE, 1998; YNTEMA, 2000): levantaram-se assim fortes reservas quanto à nossa capacidade de reconstruir a colonização da época arcaica em função das fontes literárias, bem mais tardias. R. Osborne, especialmente,

\footnotetext{
${ }^{1}$ Texto traduzido por Airton Pollini. Revisão técnica de Fábio Vergara Cerqueira.

${ }^{2}$ Maître de conférences (professora associada) d'archéologie classique à l'Université de Bourgogne - Franche-Comté, Dijon, UMR 6298 ARTEHIS, França.

${ }^{3}$ Maître de conférences (professor associado) d'histoire de l'Antiquité grecque à l'Université de Haute-Alsace (Université de Haute-Alsace, Université de Strasbourg, CNRS ArcHiMedE UMR 7044 Mulhouse), França.
} 
rejeitou a importância do modelo tradicionalmente estabelecido a propósito da relação metropolis-apoikia, e propôs uma interpretação fundada nas iniciativas privadas de indivíduos ou de grupos de indivíduos que se estabelecem em localidades favoráveis à instalação e coabitam, ao menos num primeiro momento, com as comunidades autóctonas. Desde essa "revisão", muitos especialistas se debruçaram sobre os fundamentos teóricos que permitem definir o deslocamento de populações de origem grega (ou fenícia) em uma grande parte da bacia do Mediterrâneo. De fato, os termos utilizados pelas línguas modernas condicionam, em parte, a visão que podemos forjar das realidades antigas (BOUFFIER, 2017; DE ANGELIS, 2016). O primeiro artigo do nosso dossiê tenta rever esses termos e conceitos, propondo uma visão geral das noções de diáspora, de colônia e de colonização.

Um outro aspecto importante é o da duração do fenômeno migratório, particularmente longo (do início do séc. VIII a.C. ao séc. IV a.C.). É evidente que as realidades das diferentes épocas incluídas nessa cronologia são muito variadas. Esse amplo quadro cronológico permite uma reflexão sobre os desenvolvimentos e as tendências das formas de mobilidade dos gregos no longo prazo e na escala de todo o Mediterrâneo. O objetivo é refletir sobre os elementos de continuidade e descontinuidade, sobre a retomada de modelos e práticas antigas em novos contextos históricos e sobre os fenômenos de transição (ver os artigos de A. Esposito e de C. Kormikiari). Vê-se que analogias e divergências coexistem e que, de acordo com os critérios de pesquisa selecionados, o foco é dado em umas ou outras formas. O objetivo é precisamente ir além das especialidades da história grega e observar o mundo mediterrânico antigo simultaneamente em sua globalidade e em sua diversidade. A cronologia tratada neste dossiê vai, portanto, das primeiras instalações gregas e fenícias ultramarinas até as vésperas das conquistas de Alexandre, o Grande. Os processos de instalação, as modalidades dessas instalações, a parte da iniciativa privada e o fenômeno chamado de contatos pré e proto-coloniais chamaram nossa atenção.

Se a problemática das mobilidades das comunidades gregas é tão atual, ela permeia, na verdade, a história dos estudos dos mundos gregos antigos ao longo do tempo e através de diferentes abordagens: a economia, as trocas no Mediterrâneo, a mobilidade dos indivíduos, a circulação dos objetos, a recepção de novas práticas culturais, a difusão das práticas de culto, artísticas ou políticas, as relações entre apoikiai ${ }^{4} \mathrm{e}$ metrópoles, entre colônia e interior, entre as próprias colônias, entre gregos e autóctones (cf. ÉTIENNE, 2010a; 2016). Alguns modelos historiográficos emergem com clareza: o tema dos contatos interculturais, o da construção identitária ou o da noção de etnicidade são igualmente questões muito discutidas que se situam no cerne dos debates atuais (cf. HALL, 1997; JONES, 1997; MALKIN, MÜLLER, 2012; ver nossos comentários em ESPOSITO, POLLINI, 2013; ESPOSITO, POLLINI, 2015).

\footnotetext{
${ }^{4} \mathrm{Em}$ todo o dossiê, os termos gregos foram transliterados no alfabeto latino e, por simplicidade, não marcamos os acentos, nem tônicos nem de distinção entre as vogais breves e longas (épsilon ou eta, ômicron ou ômega).
} 
Em última análise, os temas são tão variados e múltiplos que, além de algumas raras monografias, publicadas principalmente em italiano (cf. GRECO, 1992; LAMBOLEY, 1996; GUZZO, 2011; LA TORRE, 2011; TORELLI, 2011; D'ERCOLE, 2012; GUZZO, 2016), os trabalhos mais recentes se concentram, sobretudo, em alguns aspectos pontuais, ao invés de propor sínteses globais.

Na preparação deste dossiê, foi necessário fazer escolhas desde o início. A tarefa não foi fácil, o assunto é muito vasto e não foi possível tratá-lo tendo em conta todas as suas dimensões. O desafio e a maior dificuldade dessa questão estão em tentar determinar, por meio de estudos de caso, a natureza das relações mantidas no âmbito desses fenômenos de mobilidade. O conjunto é organizado em três partes. A primeira parte (A partida) contém três artigos: um relacionado às questões historiográficas (A. Esposito e A. Pollini), um segundo focando os contatos com os povos indígenas antes do estabelecimento estável dos gregos em novas terras e da fundação de colônias (apoikiai) (A. Esposito), e um terceiro sobre a mobilidade dos fenícios no Mediterrâneo (C. Kormikiari). Em seguida, o dossiê segue uma organização geográfica, onde são evocadas as principais zonas de ocupação dos gregos no Mediterrâneo na época arcaica. Primeiramente, a Itália, o primeiro destino dos colonos: na Magna Grécia (A. Pollini), na Sicília (M. B. Borba Florenzano), e nas margens do Adriático (M. P. Castiglioni). A terceira parte alcança os extremos geográficos da instalação dos gregos (Rumo ao Norte e rumo ao Oeste), tanto ao redor do Mar Negro (M. Dana) quanto nas costas mediterrâneas da Gália (C. Joncheray). Obviamente, nosso dossiê não é em nada exaustivo, tão vasto é o assunto, e muitos outros tópicos poderiam ser mencionados (as colônias gregas na Líbia, por exemplo, os fenômenos das colônias secundárias ou sub-colônias, cf. LOMBARDO, FRISONE, 2006; COSTANZI, 2009; LUNI, 2010a; 2010b; COSTANZI, 2013).

No período clássico, a experiência da instalação de cidadãos atenienses em terras confiscadas por Atenas, as clerúquias, pertence a um tipo particular de mobilidade (C. Saint-Pierre Hoffmann). Ao nosso ver, é, então, interessante colocá-lo em paralelo com as experiências do período arcaico. É importante ressaltar que as apoikiai são baseadas em um princípio de autonomia, são órgãos políticos novos e independentes. Ao contrário de outras formas de apropriação de um novo território, como as clerúquias atenienses, onde as cidades estabelecem no território de uma outra um contingente de pessoas que permanecem cidadãos de sua cidade de origem, as colônias gregas são novas entidades politicamente independentes de sua(s) metrópole(s). É evidente que as novas instalações mantêm, contudo, seus laços culturais (como o tipo de dialeto, muitas vezes a estrutura jurídica, alguns cultos ou divindades veneradas, etc.), às vezes, preservam as alianças com as cidades de origem (ver o artigo de M. Dana). O vocabulário grego não leva em conta claramente essa divisão, pois as clerúquias do séc. V a.C. ainda são, de fato, chamadas apoikiai, mas isso não significa que a distinção não seja válida (ZURBACH, 2015).

Uma última ressalva é necessária. Estamos falando quase exclusivamente da mobilidade dos gregos e dos territórios dominados por essas populações. No entanto, na Artiguidade, além das várias populações 
indígenas que estiveram diretamente em contato com os gregos nos contextos coloniais, outras civilizações tiveram igualmente experiências de mobilidade ou de expansão territorial: os fenícios fundaram Cartago na Tunísia atual, e os próprios cartagineses se apropriaram de vários lugares na África do Norte, na Península Ibérica, na Sicília e na Sardenha (ver o artigo de C. Kormikiari). Os etruscos partiram da região central da Itália, especialmente na atual Toscana, e ocuparam terras na Itália do Norte (a planície padana) e na Campânia; foram também comerciantes muito ativos em grande parte do Medierrâneo central e ocidental. Por fim, os romanos começam sua expansão pela conquista de toda a península Itálica, incluindo as antigas cidades gregas do sul, submetidas ao poder romano no séc. III a.C. Deve-se levar em consideração a variedade de situações de acordo com as regiões mediterrânicas e de acordo com a cronologia. Dentro dessa ampla gama de situações, como nossos esquemas interpretativos foram aplicados? Projetado, antes de tudo, como uma introdução para delinear as análises, a partir de uma série de exemplos, este dossiê propõe conceitos e ferramentas que permitam dar conta dos últimos resultados teóricos e metodológicos relacionados à história e à arqueologia da colonização grega, mas também, tenta definir uma prática crítica desses conceitos.

\section{UMA ABORDAGEM MULTIFOCAL E PLURIDISCIPLINAR}

Essa temática das colônias gregas levanta importantes questões não somente sobre a mobilidade dos gregos, mas também, e principalmente, sobre as diferentes perspectivas contemporâneas acerca do mundo antigo. É principalmente sobre esse aspecto que vamos nos deter no primeiro artigo deste dossiê.

Considerando os extensos contextos, geográfico, cultural e cronológico, o tema das mobilidades gregas oferece uma oportunidade para propor uma revisão dessas questões que leve em conta, também, as novas abordagens que surgiram nos últimos vinte anos. Esse balanço crítico não pode mascarar o interesse dessas novas noções, a incorporação e o uso em História Antiga de conceitos forjados em outros domínios das Ciências Humanas, a natureza transdisciplinar de nossas abordagens, tais como o uso de variadas fontes para se abrir, in fine, a novas perspectivas. Enfim, esse tipo de reflexão se torna ainda mais complexo pela interação de uma série de termos ligados entre si e que servem para se definirem de forma recíproca, como os termos "identidade", "cultura" e "etnia" ou "etnicidade", solidários, mas não sinônimos, e cujas configurações variáveis geram novas distinções (cf. ÉTIENNE, 2010; MALKIN, MÜLLER, 2012).

É natural, portanto, que a preocupação principal, no cerne da maioria de volumes recentes sobre a mobilidade grega antiga, esteja em estabelecer um panorama dos nossos avanços científicos, mas a partir de abordagens díspares. A instalação de comunidades gregas nas margens do Mediterrâneo foi um grande processo histórico que levou a profundas mudanças sociais, econômicas e culturais. Sendo o tema, por definição, multifacetado, é necessário abordá-lo sob o prisma de suas diferentes manifestações históricas, recorrendo a fontes e documentos muito variados. É por isso que pouco menos de dez especialistas se 
reuniram em torno de Sophie Collin-Bouffier para elaborar um estudo sobre a colonização e as diásporas gregas (COLLIN-BOUFFIER, 2012). Construído de acordo com uma divisão regional, o volume aborda os modos de organização política e econômica, as práticas culturais, as redes de trocas do Gibraltar ao Indo (do século VIII a.C. ao fim do século III a.C.). Sem desconsiderar as divergências próprias ao fenômeno, os gregos tinham padrões de assentamento que podiam variar em função da época e da região. Cada um dos capítulos que compõem essa obra considera essa variação sob um ângulo específico, para oferecer ao leitor uma síntese bem informada.

Em Lille, o congresso da SoPHAU (Associação francesa dos professores universitários de história antiga), realizado na Universidade Charles de Gaulle-Lille 3 e organizado por Laurianne Martinez-Sève, reuniu cerca de vinte especialistas no assunto, principalmente historiadores, mas também alguns arqueólogos. Na publicação final (MARTINEZ-SÈVE, 2012), esses especialistas traçaram um balanço historiográfico, abordando, simultaneamente, os novos dados, com o objetivo de compreender, de maneira crítica, as problemáticas mais recentes. Além disso, tratava-se de incitar o diálogo entre especialistas do Mediterrâneo arcaico com aqueles do Oriente helenístico, e reciprocamente. Suas contribuições abordam também a mobilidade das comunidades gregas estabelecidas em um espaço amplo, da Espanha à Ásia Central, e cobrindo todo o mundo grego. A obra propõe, para um período longo, que se estende por aproximadamente seis séculos, um vasto panorama sobre as modalidades de instalação e seus destinos, as relações com as populações locais, a apropriação de novos territórios, a construção de novas identidades culturais. Depois de uma seção introdutória, abordando tanto questões de vocabulário quanto questões conceituais contemporâneas, como centro e periferia, ou revisitando as tradições mitológicas, as representações mentais e simbólicas - que presidiram a mobilização dos gregos - e o papel do santuário délfico nessas dinâmicas, vêm vários capítulos organizados de maneira regional: o Mediterrâneo central e oriental, o Mar Negro e a Propôntida, os Balcãs, o Egito... Para cada uma dessas regiões, um objetivo duplo impulsiona as sínteses dos autores: traçar avaliações historiográficas e científicas, e destacar os desenvolvimentos atuais da pesquisa, levando em conta, entre outras coisas, as redes de relações e de solidariedade ao longo do mundo mediterrânico e ao longo do Oriente Médio.

Em Nanterre, o congresso organizado por Laurent Capdetrey e Julien Zurbach (CAPDETREY, ZURBACH, 2012) resultou em uma obra coletiva que se apresenta, também, tanto como um balanço historiográfico e epistemológico quanto como uma oportunidade para aprofundar e avaliar conceitos largamente utilizados na literatura atual. Em primeiro lugar, aqueles das redes (redes comerciais, intelectuais, alianças políticas) estão no centro da maior parte das contribuições, de maneira mais ou menos explícita. O volume oferece, assim, uma síntese crítica das reflexões e dos avanços sobre essas questões, mas também sobre as noções de mobilidade e de etnicidade, e sobre a contribuição desses conceitos para o estudo das comunidades gregas e de sua evolução entre o período arcaico e o início do período helenístico. 
O arco cronológico é deliberadamente amplo para permitir uma reflexão sobre as transformações das formas de mobilidade - individuais ou coletivas - dos gregos, ao longo do tempo e em todo o Mediterrâneo ( $c f$. as propostas de L. Capdetrey, na introdução). Os vários autores abordam as noções-chave da obra - redes, mobilidade, etnicidade - nos respectivos domínios de pesquisa, a partir de um tema específico (as ânforas, o mobiliário funerário, a demografia, as fontes, etc.), mas, sobretudo, para a maioria deles, em um processo que convida também a definir uma prática crítica desses mesmos conceitos.

No âmbito dos concursos para se tornar professor no ensino secundário francês (o CAPES e a Agrégation), a publicação, em 2012, de vários livros em língua francesa dedicados às diásporas gregas teve como consequência chamar a atenção sobre uma série de problemáticas que, apesar do interesse de diversos pesquisadores, eram assuntos restritos somente a especialistas. Nesses volumes, tratou-se de incitar o diálogo entre um arqueólogo e um historiador, um especialista da literatura e um ceramólogo, um epigrafista e um numismata. A arqueologia (por meio do estudo das necrópoles, da cultura material, dos mobiliários funerários, das cerâmicas, das organizações urbanas e territoriais) constitui, de fato, um recurso fundamental, uma vez que permite encontrar, em campo, os vestígios dos estabelecimentos fundados pelos gregos, e apreender, por intermédio das produções materiais, a natureza dos contatos interculturais com as sociedades indígenas. Ela representa uma fonte primordial para os primeiros contatos, para as questões ligadas à cronologia de uma fundação ou à expansão territorial de uma nova cidade, especialmente no que diz respeito ao período arcaico. Mas ela é passível de debate e condicionada pelas tradições intelectuais específicas a cada período e, por vezes, a cada área. As inscrições, que são testemunhos diretos, também fornecem informações de interesse preponderante para compreender o funcionamento de algumas cidades, as relações políticas e diplomáticas, a organização social, as conexões entre as redes de circulação, práticas comerciais e desenvolvimento da escrita. Os dados mais numerosos provêm principalmente das fontes literárias, dos autores mais antigos - incluindo algumas informações dos poetas Homero e Arquíloco - mas principalmente dos historiadores, Heródoto e Tucídides, e dos filósofos, Platão e Aristóteles.

Além disso, o tema das diásporas impõe imediatamente uma abordagem multifocal e pluridisciplinar. Seu estudo apresenta muitas dificuldades: de fato, é importante ter-se em mente as diferenças, por vezes bastante grandes, entre as datas de fundação das diferentes colônias estudadas, mas também os contrastes entre suas origens diversas, sua integração no seu contexto regional, suas aproximações e seus conflitos. Existe, igualmente, um claro desequilíbrio nos corpus de fontes, assim como na bibliografia disponível, dependendo das cidades consideradas.

Os contatos com o mundo grego assumiram formas diversas e descontínuas: relações de troca, conflitos militares ou deslocamentos individuais. Esses contatos interculturais, vistos através das relações dialéticas com os indígenas, implicavam diversas interações - e não somente "influências" - exercidas reciprocamente, o que não excluía a existência de passarelas entre os diferentes grupos étnicos, incluindo a 
existência de casamentos inter-étnicos e de alianças matrimoniais (ESPOSITO, ZURBACH, 2010 ; ESPOSITO, POLLINI, no prelo). O casamento aparece, de fato, como uma das formas preferidas da mestiçagem étnica: ele pôde facilitar os processos de mobilidade entre as elites. Esses contatos interculturais podiam, portanto, dar origem a fenômenos de integração ou de rejeição, mas os dois casos recobriam fenômenos mais complexos, como a apropriação e a ressemantização pelas elites indígenas de elementos materiais (e imateriais) gregos, servindo para sua própria ideologia (o symposion, por exemplo: ESPOSITO, 2015), ou mesmo a integração, na cidade grega, de populações não-gregas, originando situações linguísticas complexas. Os limites territoriais e étnicos não constituíram barreiras intransponíveis.

O dossiê que apresentamos tem o objetivo de propor uma análise dos modos de elaboração da identidade grega em ambiente colonial que leve em conta a complexidade das situações estudadas. Certamente, o objetivo é fazer eco aos desenvolvimentos recentes da pesquisa na França sobre os temas relacionados à mobilidade dos gregos. Mas este dossiê pretende também incitar um diálogo, em si multidisciplinar, convidando os colegas brasileiros, com uma longa tradição de estudos sobre as colonizações modernas e interessados nos fenômenos coloniais antigos, a emitir reações e comparações, assim como reflexões sobre as práticas teóricas que envolvem toda e qualquer experiência colonial. A leitura das respostas às diversas situações de contato intercultural - entre gregos, fenícios, etruscos, indígenas -, nos diferentes contextos geográficos e históricos, só pode contribuir para uma melhor compreensão dos fenômenos de mobilidade no Mediterrâneo Antigo, desde que, no entanto, se insista nas variações (de acordo com a época e, para cada período, de acordo com os agentes e os parceiros das trocas). Certamente, os conceitos mobilizados nas diferentes áreas selecionadas não são exatamente equivalentes, mas a análise atribuída a eles deve permitir gerar analogias e diferenças por vezes decisivas, significativas. Trata-se, portanto, a nosso ver, de um campo de estudo particularmente fértil. A diversidade das experiências apresentadas aqui mostra a grande variedade dos campos de experimentação da mobilidade humana antiga e o dinamismo de certas sociedades antigas. Quais orientações dar à pesquisa? Quais metodologias? Ainda assim, este é um processo em curso, um work in progress. Tal pesquisa se insere em uma reflexão mais ampla sobre a natureza das trocas e das redes no espaço mediterrânico. 


\section{BIBLIOGRAFIA}

BOUFFIER, SOPHIE. "Migrations et mobilités antiques: l'exemple des Grecs en Méditerranée ». In: DOMINIQUE GARCIA et HERVÉ LE BRAS (ed.), Archéologie des migrations. Paris: La Découverte/Inrap, 2017, p. 153-166.

CAPDETREY, LAURENT et ZURBACH, JULIEN (eds.). Mobilités grecques. Mouvements, réseaux, contacts en Méditerranée, de l'époque archaïque à l'époque hellénistique. Scripta Antiqua, 46, Bordeaux: Ausonius, 2012.

COLLIN-BOUFFIER, SOPHIE (ed.). Les diasporas grecques du détroit de Gibraltar à I'Indus, VIII' siècle av. J.-C.fin du III siècle av. J.-C. Pour les concours. Série Cours, Paris: Sedes, 2012.

COSTANZI, MICHELA. " Les fondations grecques de deuxième degré en Italie du Sud et en Sicile: amies des "autres", ennemies des Grecs? ». REA 111, 2009, p. 429-451.

COSTANZI, MICHELA. «Invitation à une nouvelle réflexion sur les fondations grecques en Libye ». Revue des études grecques 126, 2013, p. 345-370.

D'ERCOLE, MARIA CECILIA. Histoires méditerranéennes: aspects de la colonisation grecque de l'Occident à la mer Noire, VIII-IVe siècles av. J.-C., coll. Les Hespérides, Paris: Errance, 2012.

DE ANGELIS, FRANCO. «E pluribus unum: the multiplicity of models ». In: LIEVE DONNELLAN, VALENTINO NIZZO and GERT-JAN BURGERS (eds.). Conceptualising early colonisation, Contextualising early colonisation II. Bruxelles: Institut historique belge de Rome, 2016, p. 97-104.

DOMÍNGUEZ, ADOLFO J. "The origins of Greek colonisation and the Greek polis: some observations ». Ancient West and East (AWE) 10, 2011, p. 195-207.

DONNELLAN, LIEVE, NIZZO, VALENTINO et BURGERS, GERT-JAN (eds.). Contexts of early colonization. Contextualizing early colonization I. Rome: Palombi, 2016a.

DONNELLAN, LIEVE, NIZZO, VALENTINO et BURGERS, GERT-JAN (eds.). Conceptualising early colonisation. Contextualizing early colonization II. Bruxelles: Institut historique belge de Rome, 2016b.

ESPOSITO, ARIANNA (ed.). Autour du "banquet" : modèles de consommation et usages sociaux. Dijon: Éditions universitaires de Dijon, 2015.

ESPOSITO, ARIANNA et POLLINI, AIRTON. « Relations interculturelles en Grande Grèce et Sicile ». In: ANTONIO GONZALES et MARIA TERESA SCHETTINO (eds.). Le point de vue de l'autre. Relations culturelles et diplomatiques. Dialogues d'Histoire Ancienne, Supplément 9, Besançon: Presses universitaires de Franche-Comté, 2013, p. 17-38.

ESPOSITO, ARIANNA et POLLINI, AIRTON. « Penser les métissages en Grande Grèce et en Sicile ». In: SILVIA CAPANEMA, QUENTIN DELUERMOZ, et alii (eds.). Du transfert culturel au métissage. Concepts, acteurs, pratiques. coll. Histoire. Rennes: Presses universitaires de Rennes, 2015, p. 49-71. 
ESPOSITO, ARIANNA et POLLINI, AIRTON. « Post-colonialism from America to Magna Graecia ». In: LIEVE DONNELLAN, VALENTINO NIZZO et GERT-JAN BURGERS (eds.). Conceptualising early colonisation. Contextualising early colonisation II. Bruxelles: Institut historique belge de Rome, 2016, p. 61-75.

ESPOSITO, ARIANNA et POLLINI, AIRTON (prelo). « Género, identidades y cultura material a través de algunos estudios de casos de la Península itálica ». In: MANEL GARCÍA SANCHÉZ et RENATA SENNA GARRAFFONI (eds.). Género y cultura material. coll. Instrumenta. Barcelona: Universitat de Barcelona.

ESPOSITO, ARIANNA et ZURBACH, JULIEN. « Femmes indigènes et colons grecs: quelques observations ». In: PIERRE ROUILLARD (ed.). Portraits de migrants, portraits de colons. coll. Colloques de la Maison René-Ginouvès. 6, 2, Paris: De Boccard, 2010, p. 51-70

ÉTIENNE, ROLAND (ed.). La Méditerranée au VIIe siècle av. J.-C. essais d'analyses archéologiques. Travaux de la Maison René Ginouvès, 7. Paris: De Boccard, 2010a.

ÉTIENNE, ROLAND. « Historiographie, théories et concepts ». In: ROLAND ÉTIENNE (ed.). La Méditerranée au VII siècle av. J.-C. Essais d'analyses archéologiques. coll. Travaux de la Maison René Ginouvès, 7. Paris: De Boccard, 2010b, p. 3-26.

ÉTIENNE, ROLAND. "Connectivité et croissance: deux clés pour le VIII ${ }^{\mathrm{e}}$ s.? ». In: LIEVE DONNELLAN, VALENTINO NIZZO et GERT-JAN BURGERS (eds.). Conceptualising early colonisation. Contextualising early colonisation II. Bruxelles: Institut historique belge de Rome, 2016, p. 89-95.

GRECO, EMANUELE. Archeologia della Magna Grecia. Rome-Bari: Laterza, 1992.

GRECO, EMANUELE. «On the Origin of the Western Greek Poleis », Ancient West and East (AWE), 10, 2011, p. 233-242.

GUZZO, PIER GIOVANNI. Fondazioni greche. L'Italia meridionale e la Sicilia (VIII e VII sec. a.C.). coll. Studi superiori, 691, Archeologia. Roma: Carocci editore, 2011.

GUZZO, PIER GIOVANNI. De Pithécusses à Pompéi. Histoires de fondations. Quatre conférences au Collège de France (Paris, 2014). coll. Études, 10. Naples: Centre Jean Bérard, 2016.

HALL, JONATHAN M. Ethnic identity in Greek antiquity. Cambridge: Cambridge University Press, 1997.

JONES, SîAN. The Archaeology of ethnicity. Constructing identities in the past and present. Londres: Routledge, 1997.

LA TORRE, GIOACCHINO FRANCESCO. Sicilia e Magna Grecia. Archeologia della colonizzazione greca d'Occidente. coll. Manuali Laterza. Roma: Laterza, 2011.

LAMBOLEY, JEAN-LUC. Les Grecs d'Occident. La période archaïque. Paris: Cedes, 1996.

LOMBARDO, MARIO et FRISONE, FLAVIA (eds.). Colonie di colonie. Le fondazioni sub-coloniali greche tra colonizzazione e colonialismo. Lecce: Congedo editore, 2006. 
LUNI, MARIO (ed.). Cirene nell'Antichità: XI Convegno internazionale di archeologia cirenaica, 30 giugno-2 Iuglio 2006. Cirene "Atene d'Africa", 2. Roma: L'Erma di Bretschneider, 2010a.

LUNI, MARIO (ed.). Cirene e la Cirenaica nell'Antichità: XI Convegno internazionale di archeologia cirenaica, 30 giugno-2 luglio 2006. Cirene "Atene d'Africa", 3. Roma: L'Erma di Bretschneider, 2010b.

MALKIN, IRAD. " Exploring the validity of the concept of 'foundation': a visit to Megara Hyblaia ». In: VANESSA B. GORMAN et ERIC W. ROBINSON (eds.). Oikistes: studies in constitutions, colonies, and military power in the ancient world, offered in honor of A.J. Graham. coll. Mnemosyne. Supplementum, 234, Leiden: Brill, 2002, p. 195-225.

MALKIN, IRAD. « Postcolonial Concepts and Ancient Greek Colonization ». MLQ: Modern Language Quarterly $65,3,2004$, p. 341-364.

MALKIN, IRAD et MÜLLER, CHRISTEL. "Vingt ans d'ethnicité: bilan historiographique et application du concept aux études anciennes », In: LAURENT CAPDETREY et JULIEN ZURBACH (eds.). Mobilités grecques. Mouvements, réseaux, contacts en Méditerranée, de l'époque archaïque à l'époque hellénistique. coll. Scripta Antiqua, 46, Bordeaux: Ausonius, 2012, p. 25-37.

MARTINEZ-SÈVE, LAURIANNE (ed.). Les Diasporas grecques du VIII à la fin du III siècle av. J.-C. Pallas, 89. Toulouse: Presses universitaires du Mirail, 2012.

OSBORNE, ROBIN. « Early Greek Colonization? The Nature of Greek Settlement in the West ». In NICK FISHER et HANS VAN WEES (eds.). Archaic Greece: New Approaches and New Evidence. Londres: Duckworth, 1998, p. 251-269.

TORELLI, MARIO. Dei e artigiani: archeologie delle colonie greche d'Occidente. coll. Grandi Opere. Bari: Laterza, 2011.

YNTEMA, DOUWE GEERT. "Mental landscapes of colonization: the ancient written sources and the archaeology of early colonial-Greek southeastern Italy ", Babesch, 75, 2000, p. 1-49.

ZURBACH, JULIEN. "Confiscation, conquête et colonisation dans les cités grecques ", Mélanges de l'École française de Rome - Antiquité [on line], 127-2 | 2015, URL : <http://mefra.revues.org/2857> 


\section{FIGURAS}

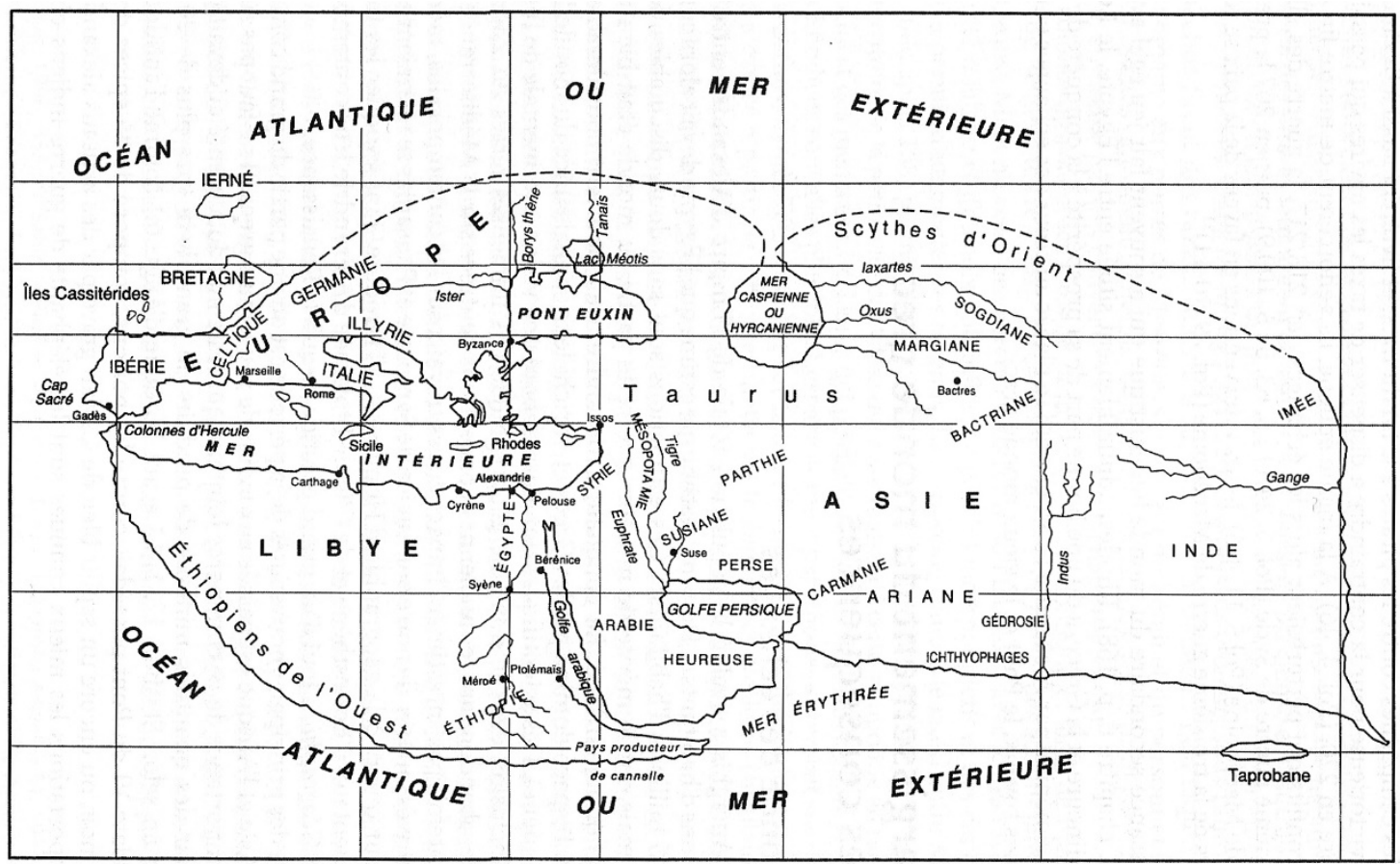

Figura 01: Mapa do mundo conhecido (oikoumene) de acordo com as descrições na obra do geógrafo Estrabão (segundo Chr. Jacob, Géographie et ethnographie en Grèce ancienne, Paris, A. Colin, 1991, p. 113).

\section{A COLONIZAÇÃO GREGA}

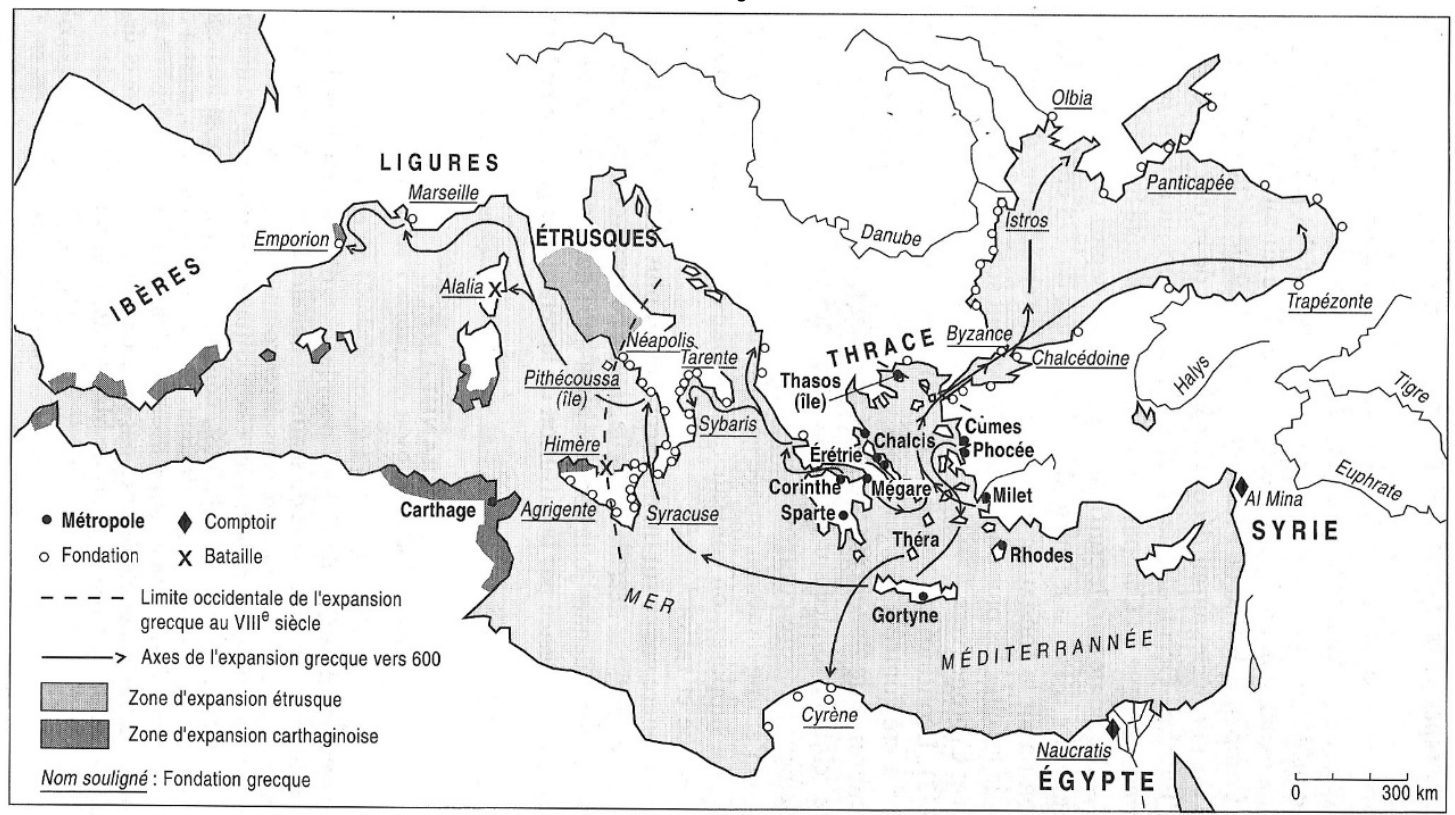

Figura 02: Mapa da colonização grega no período arcaico (segundo M.-Fr. Baslez, Histoire politique du monde grec antique, Paris, Nathan, 2004, p. 53). 